\title{
A geological fingerprint of low-viscosity fault fluids mobilized during an earthquake
}

\author{
E. E. Brodsky, ${ }^{1}$ C. D. Rowe, ${ }^{2}$ F. Meneghini, ${ }^{1}$ and J. C. Moore ${ }^{1}$ \\ Received 14 February 2008; revised 15 September 2008; accepted 10 October 2008; published 9 January 2009.
}

[1] The absolute value of stress on a fault during slip is a critical unknown quantity in earthquake physics. One of the reasons for the uncertainty is a lack of geological constraints in real faults. Here we calculate the slip rate and stress on an ancient fault in a new way based on rocks preserved in an unusual exposure. The study area consists of a fault core on Kodiak Island that has a series of asymmetrical intrusions of ultrafinegrained fault rock into the surrounding cataclasite. The intrusive structures have ductile textures and emanate upward from a low-density layer. We interpret the intrusions as products of a gravitational (Rayleigh-Taylor) instability where the spacing between intrusions reflects the preferred wavelength of the flow. The spacing between intrusions is $1.4 \pm 0.5$ times the thickness of the layer. This low spacing-to-thickness ratio cannot be explained by a low Reynolds number flow but can be generated by one with moderate Reynolds numbers. Using a range of density contrasts and the geometry of the outcrop as constraints, we find that the distance between intrusions is best explained by moderately inertial flow with fluid velocities on the order of $10 \mathrm{~cm} / \mathrm{s}$. The angle that the intrusions are bent over implies that the horizontal slip velocity was comparable to the vertical rise velocity, and therefore, the fault was slipping at a speed of order $10 \mathrm{~cm} / \mathrm{s}$ during emplacement. These slip velocities are typical of an earthquake or its immediate afterslip and thus require a coseismic origin. The Reynolds number of the buoyant flow requires a low viscous stress of at most $20 \mathrm{~Pa}$ during an earthquake.

Citation: Brodsky, E. E., C. D. Rowe, F. Meneghini, and J. C. Moore (2009), A geological fingerprint of low-viscosity fault fluids mobilized during an earthquake, J. Geophys. Res., 114, B01303, doi:10.1029/2008JB005633.

\section{Introduction}

[2] In order to successfully model the initiation, propagation or arrest of an earthquake, quantitative measures of the absolute resisting stresses on faults are necessary. Unfortunately, these stresses are still uncertain. Seismology alone cannot measure absolute stresses [Abercrombie et al., 2006]. Rock mechanics suggests that the absolute stress between two solid rocks should be on the order of the lithostatic stress [Byerlee, 1970]. However, heat flow studies fail to measure the implied frictional heating [Lachenbruch and Sass, 1980, 1992]. Furthermore, recent laboratory and theoretical work suggests that qualitatively different processes are active at high slip rates that fundamentally change the resisting stresses [Andrews, 2002; Brodsky and Kanamori, 2001; Fialko and Khazan, 2005; Nielsen et al., 2008; Rice, 2006; Spray, 2005; Yuan and Prakash, 2008]. Ground truth for these proposals is limited because there are few tools to determine the slip rate of

\footnotetext{
${ }^{1}$ Department of Earth and Planetary Science, University of California, Santa Cruz, California, USA.

${ }^{2}$ Department of Geological Sciences, University of Cape Town, Cape Town, South Africa.

Copyright 2009 by the American Geophysical Union. 0148-0227/09/2008JB005633\$09.00
}

ancient faults and almost no recognized record of the seismic stresses [Cowan, 1999].

[3] Here we present observations and analysis of an unusual site that can help constrain the local absolute stresses on a fault. The faulting preserved at the key outcrop occurred at $12-14 \mathrm{~km}$ depth in a megathrust in an accretionary prism that is now exposed on Kodiak Island, Alaska [Rowe et al., 2005; Rowe, 2007]. The fault core is composed of a $\sim 3.5 \mathrm{~cm}$ layer of ultrafine-grained black rock that is embedded in a $13.5 \mathrm{~m}$-thick cataclasite that is interpreted as a subduction thrust by Byrne [1984] (Figures 1 and 2). A series of cusped intrusions that extend upward from the core are interpreted as buoyant intrusions into the overlying layer. Such gravitational (Raleigh-Taylor) instabilities are general features of layered materials whenever a higherdensity layer overlies a lower density layer and both layers behave ductilely. This study analyzes the spacing of the intrusions using a fluid dynamic model in order to: (1) determine the emplacement speed and thus provide a new geological tool to identify seismogenic faults in the geological record and (2) constrain the rheology and local stress on the fault during emplacement.

[4] Ultrafine-grained fault rocks like the one studied here have been the subject of intense scrutiny in previous work [Sibson and Toy, 2006]. The major debate revolves around whether or not the unit is a frictional melt (pseudotachylyte) or an ultracataclasite [Di Toro et al., 2005; Magloughlin and 


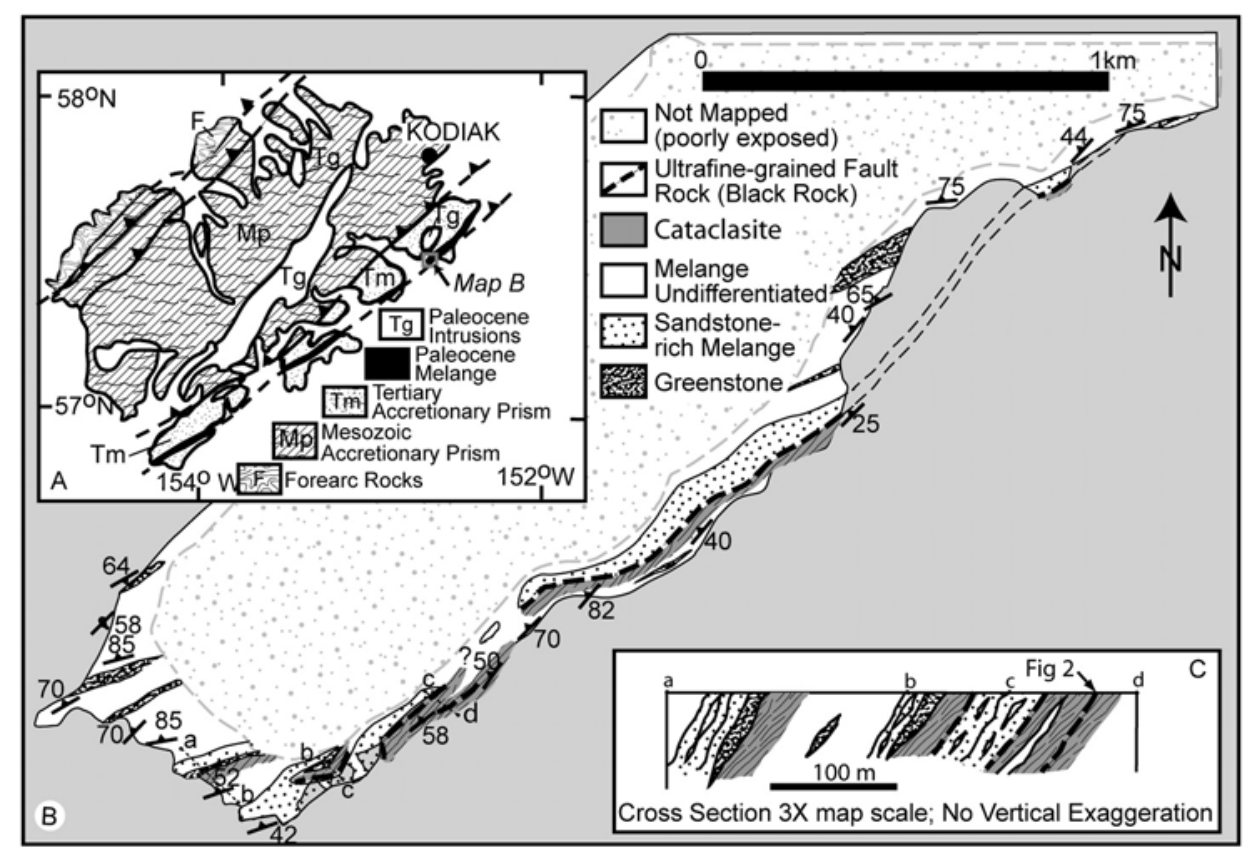

Figure 1. Geologic map of Pasagshak Peninsula showing location of ultrafine-grained fault rock, i.e., the "black rock" that is the subject of this paper. (a) Regional location map. (b) Map of Pasagshak Peninsula. Thickness of black rock is exaggerated to better show its location and its lateral extent of $2.5 \mathrm{~km}$. (c) Cross-section. Note that black rock occurs in three layers. Only the structurally lowest black rock layer is included in the associated cataclasite; the others occur at the boundary with sandstone beds. Surface datum for cross-section is sea level, and three separate subsections connect through equivalent structural positions along strike. The position of the photo in Figure 2 is marked on the cross-section in inset C. Figure modified from Rowe et al. [2005, Figure 1].

Spray, 1992; Rowe et al., 2005; Wenk et al., 2000]. Petrological and geochemical techniques are fast developing to resolve the issue [Lin, 2007]. Here we present an alternative approach. Rather than directly constraining the chemistry, temperature or mineralogy of the unit, we will instead measure its geometry to constrain the rheology. As will be discussed near the end of the paper, the rheology inferred from the flow analysis is consistent with either a granular flow or a frictional melt origin as suggested by previous work at this site [Meneghini et al., 2007; Rowe et al., 2005]. Therefore the new technique is complementary to the previously explored ones. In order to emphasize that no prior knowledge about the genesis of the unit is necessary for the flow analysis, we will postpone a discussion of the correct classification of the ultrafine-grained fault rock to the final section of this paper. For the bulk of the paper, we will keep the discussion general by simply referring to the ultrafine-grained fault rock as the "black rock."

[5] This paper begins with the geological observations. After reviewing the geological context that is more fully documented elsewhere, we present the central observations of this paper: the intrusions at the Kodiak Island site. We will highlight the features indicative of ductile, buoyant behavior both by describing the outcrop and comparing it to similar structures formed by gravitational instabilities in sedimentary rocks. We will then proceed to interpret the spacing of the intrusions in terms of the fluid dynamics with the aid of a linear stability analysis. In order to explain the data, we will incrementally add complications to the model and ultimately conclude that nonnegligible inertia in the fluid is necessary. The analysis results in a constraint on the strain rate of the flow. Finally, we will determine the velocity and stress at the time of intrusion and interpret these in terms of the rheologies of plausible materials in the fault.

\section{Observations}

\subsection{Geological Context}

[6] The Kodiak accretionary complex of Alaska is an exhumed subduction zone that has modern analogs locally offshore in the Eastern Aleutian Trench [Plafker et al., 1994]. Plate boundary thrust faults are preserved as mélanges in several accreted units. These mélanges have been interpreted by previous workers as ancient decollements formed during subduction to $\sim 12-14 \mathrm{~km}$ [Byrne, 1984; Vrolijk et al., 1988]. The stratigraphic younging directions of the surrounding geological units indicate that the current upward direction preserves the original orientation [Rowe, 2007].

[7] Within one mélange, four parallel, high-strain, strongly foliated cataclastic shear zones occur within a structural thickness of $300 \mathrm{~m}$ (Figure 1). Compositional data suggest that the cataclastic shear zones are derived from the surrounding mélange but are differentiable from it in texture and thickness. The thickness of the of individual bands where measured was $31 \mathrm{~m}, 14 \mathrm{~m}, 25 \mathrm{~m}$ and $14 \mathrm{~m}$ in order from west to east (structurally downsection) across Figure 1. Cataclasites are composed of submillimeter to decimeter sandstone fragments in a matrix of fine-grained pelitic 

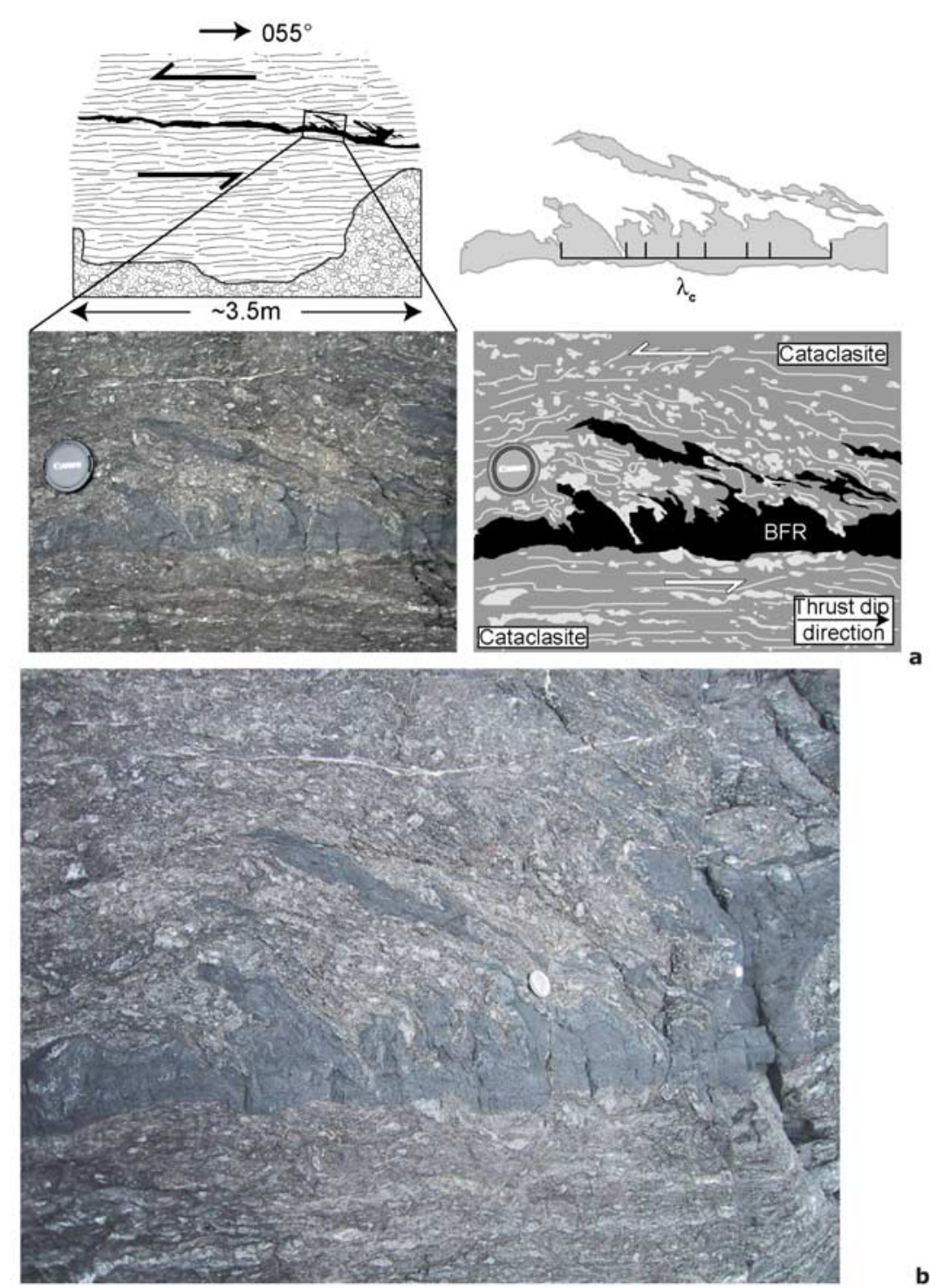

Figure 2. Photograph and explanatory sketch of the outcrop of black rock in Kodiak Island, AK. Lens cap diameter on bottom pictures is $6 \mathrm{~cm}$ for scale. (a) Upper left sketch shows general outcrop-scale appearance of black rock layer cutting at a low angle the cataclasite fabric (thin discontinuous lines mark structural fabric). Close-up view in lower photograph and sketch show ductile intrusions of black material in hanging wall cataclasite. Cataclasite fabric is locally disrupted around intrusions (see fabric around lens cap and compare it with subplanar fabric of lower cataclasite layer), suggesting that cataclasites were able to ductilely deform at time of intrusion and did not respond in a brittle manner to upward flow. Deflection of the intrusive structures due to shear consistent with thrust motion is also visible, especially in taller intrusions. Upper right inset illustrates only the intrusion geometry, showing the spacing between intrusions as measured on the outcrop. These intervals are used as proxies for wavelengths in calculations. (b) Alternative angle on the same exposure showing that the isolated black rock patches on the far right of the photograph in Figure 2a are the distended peaks of more intrusions. Wavelengths can only be measured on the intrusions where the connection to the source layer is fully exposed. All 7 examples with sufficient exposure have been measured in Figure 2a and included in this paper.

material. The cataclasites show a scaly foliation due to pressure solution superimposed on the cataclastic texture [Rowe, 2007]. Within each shear zone, the cataclasite textures vary at field-scale in clast concentration, strength/ style of foliation and degree of shearing [Rowe et al., 2005]. Textural domains can be bounded by either thin shear surfaces or have gradational relationships to one another.
[8] The cataclasite bands are interpreted as episodes of localized of deformation in the decollement evolution and are more fully documented by Rowe [2007]. They show that the paleodecollment was a series of anastomosing surfaces rather than repeated faulting on a single thrust surface [Rowe et al., 2005]. On the basis of previous work on accretionary prism development, the simplest interpretation 
is progressive accretion by underplating at the base resulting in the structurally highest cataclasite being the oldest [Sample and Fisher, 1986]. The order of individual cataclasite band activity does not have any direct bearing on the interpretation here.

[9] Evidence of extreme strain localization in the cataclastic fault zones manifests as decimeter-thick planar to irregular beds of dark gray to black ultrafine-grained fault rocks that cut and complexly intrude three of the cataclasites. The thickest cataclasite band contains no black rock. The black layers occur within the cataclasite or at the sharp boundary between the shear zone and a bounding 3-10 m thick massive sandstone unit from the mélange. The black rocks in the fault are exceptionally continuous for distances of more than $2.5 \mathrm{~km}$ in layers that are subparallel to the strike of the cataclasite bands (Figure 1).

[10] These black rock layers are distinguished in the field by hardness, black color and vitreous to earthy luster. Microscopy has confirmed that the black rock textures sharply contrast with those observed in the cataclasites. The black rocks have: (1) ultrafine grains ranging from 1 to 10 microns, as opposed to the cataclasite grains ranging from the submillimeter scale to tens of centimeters, (2) subrounded quartz and plagioclase as opposed to rounded grains, (3) a matrix containing tabular euhedral, zoned plagioclase crystals as opposed to uniform anhedral plagioclase and (4) no preferred orientation of platy minerals at any scale, as opposed to scaly foliation [Meneghini et al., 2008].

[11] The chemistry of the black rocks is consistent with being derived from the cataclasite. The major mineral constituents for both units are quartz, albite, chlorite and illite. The mean chemical composition of the two units is within the standard deviation of the measurements for all major elements except $\mathrm{Na}_{2} \mathrm{O}$ (Table B1). This minor differences in bulk chemistry suggest minor fractionation between the cataclasite and the black rock, possibly due to incomplete melting [Meneghini et al., 2007]. In particular, the ultrafinegrained matrix of the black rocks is slightly depleted in phyllosilicates and enriched in tabular albitic feldspar relative to the cataclasites. However, the overall similarities indicate a close relationship between the units.

\subsection{Black Rock Intrusions}

[12] In one locality where the black rock is entirely embedded in the cataclasite, flame-like intrusions of black rock originate from the black rock layer and enter the upper cataclasite (Figure 2). Here the cataclasite is $14 \mathrm{~m}$ thick. The black rock is inside a $0.3 \mathrm{~m}$ thick sandstone clast-rich textural domain of the cataclasite.

[13] The intrusions taper with distance upward from the black rock and terminate within $0.1 \mathrm{~m}$ of the interface. The smoothly curved forms imply ductile deformation. Pointed cusps in ductile rocks are commonly interpreted as indicative of the relative viscosity of the two layers because the lower viscosity unit forms smaller angles as it is more easily deformed [Davis and Reynolds, 1996; Dieterich and Onat, 1969]. In this case, the elongate tips of the black rock intrusions indicate that the black rock is less viscous than the overlying cataclasite.

[14] The base of the black layer is smooth with no intrusions extending downward from the layer. The vertical asymmetry suggests that the intrusions are buoyant features
Table 1. Density Measurements ${ }^{\mathrm{a}}$

\begin{tabular}{lcc}
\hline \multicolumn{1}{c}{ Unit } & Mean $\left(\mathrm{kg} / \mathrm{m}^{3}\right)$ & Standard Deviation $\left(\mathrm{kg} / \mathrm{m}^{3}\right)$ \\
\hline Black rock-bulk & 2685 & 19 \\
Cataclasite-bulk & 2722 & 23 \\
Sandstone-bulk & 2683 & 7 \\
Black rock-grain & 2726 & 45 \\
Cataclasite-grain & 2849 & 19 \\
\hline
\end{tabular}

${ }^{\text {a }}$ Reported values are the dry bulk density of eight cataclasite, seven black rock, and two sandstone samples and grain density on three powdered samples. We measured the volume of 1-in. core or sawed rectangular solid samples and the volume of powders with a Quantachrome gas comparison pycnometer. We determined mass with a scale sensitive to $10^{-6} \mathrm{~kg}$. Up to four repeat measurements were performed on most samples with standard deviations of $0.5 \%$.

driven by a density contrast between the less dense black rock and the more dense upper cataclasite. To investigate whether the density difference between the units is significant, we measured the densities of the preserved rocks (Table 1). The grain density of the black rock is presently 5\% less than the surrounding cataclasites. The difference is explained by a slight depletion of sheet silicate minerals in the black rock [Meneghini et al., 2008]. The preserved porosity in the black rock is less than in the cataclasite, so the net density difference is now $1.4 \%$ with a standard deviation of $1.1 \%$.

[15] Extrapolating the measured densities to emplacement conditions requires knowledge of the genesis of the black rock. We will derive a range of possible in situ density changes by considering two end-member candidates for generating the black rocks: melting and granular flow. Melting of the cataclasite composition reported in Appendix $\mathrm{B}$ in bulk and subsequent heating to $1400^{\circ} \mathrm{C}$ reduces the theoretical density by $20 \%$ relative to the preserved density as calculated with the thermodynamic MELTS model via the Conflow software [Mastin and Ghioroso, 2000]. Mobilized granular flow dilates via intergranular collisions. Under confined, high-pressure conditions, the maximum dilatation corresponds to the random-loose-packing of the grains. The most dispersed random-loose-packing function is that of monodispersed spheres which has a solid volume fraction of 55\% [Song et al., 2008]. If the grains are in this state and the intergranular region is filled with water with a density of $1000 \mathrm{~kg} / \mathrm{m}^{3}$, the density of the mixture is $\sim 30 \%$ less than the bulk cataclasite. The actual expansion of a natural granular medium must be less than this extreme bound as the grains are neither spherical nor mono-dispersed. In summary, either situation (melting or granular flow) reduces the black rock density relative to the cataclasite and thus supports the inference of a buoyantly driven intrusion.

[16] The intrusive structures are sheared in a direction consistent with motion on the thrust as inferred by kinematic indicators in the cataclasite and mélange (bending leftward in Figure 2) [Rowe, 2007]. The cross-section is within $10^{\circ}$ of parallelism to the mean transport direction in the cataclasite. The taller intrusions, such as that in the center of Figure 2, are progressively inclined with increasing distance from the source layer of black rock, varying from $15^{\circ}$ from vertical at the base to $68^{\circ}$ at the crest. Above the contiguous intrusions, even longer features are stretched out to be coplanar with the fault surface. The shape indicates the intrusions were sheared at the same time as they grew vertically so that the points furthest from the fault surface accumulated the most shear. 


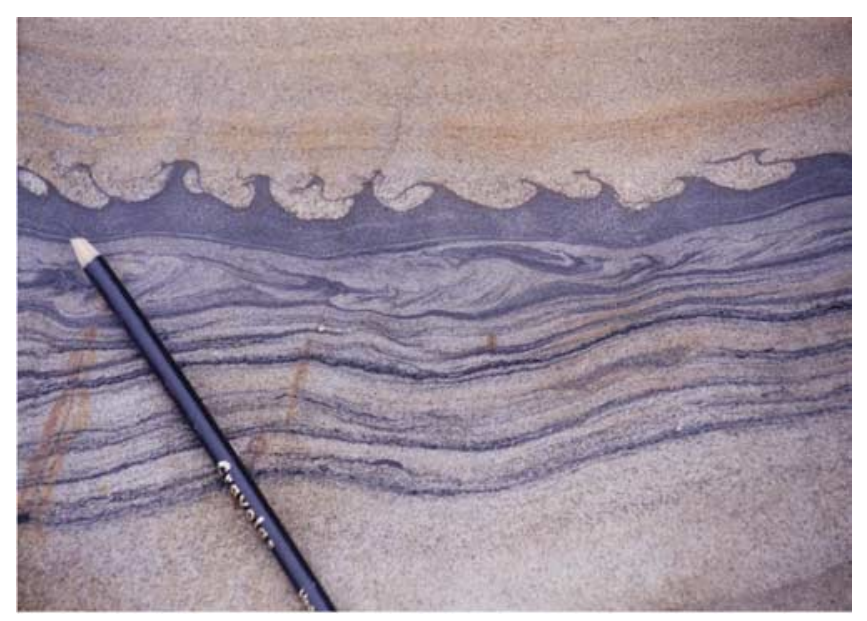

Figure 3. Sedimentary flame structures, Carmelo Formation, Pt. Lobos, California. Pencil diameter is $8 \mathrm{~mm}$. Note systematic spacing and direction of deflection and intrusion perpendicularity to basal bedding contact.

[17] The deformation of the intrusions is gradational throughout the intrusive zone without any sign of relative overprinting or cross-cutting, so horizontal and vertical motions were simultaneous. The inclination of the eight measurable intrusive structures averaged over their entire heights is $38^{\circ} \pm 15^{\circ}$ from vertical and thus the horizontal and vertical velocities are comparable. Therefore, by constraining the emplacement rate of the structures, we learn about the shear rate during their formation.

[18] Even though the overlying layer is stiffer than the black rock, flow occurred in the cataclasite to accommodate the growing intrusions. This deformation is recorded by the curvature of the otherwise planar fabric in the cataclasite between the intrusions (see the fabric between the lens cap and the black fault rock in Figure 2). The fabric stretches and bends so that it remains parallel to the curved black rock-cataclasite boundary between intrusions. The cataclastic fabric provides evidence that the intrusions spacing is not governed by post-emplacement layer-parallel shortening because the fabric is subparallel $0.3 \mathrm{~m}$ above and directly below the fault core.

[19] The ductile textures occur exclusively where granular cataclasite overlies a horizon of black rock. Elsewhere, sandstone overlies the black rock and the black rock intrudes through brittle fractures. The presence of deformable granular cataclasite appears to be required to generate the ductile intrusions.

[20] Individual intrusions are spaced closely together relative to the thickness of the layer. Over seven measurable intrusion intervals (tick marks in Figure 2), the spacing is $4.7 \pm 1.5 \mathrm{~cm}$ and the layer thickness is $3.5 \pm 0.6 \mathrm{~cm}$ where the error ranges are 1 standard deviation. Spacing of the intrusions is measured between minima along a median line defined by the layer thickness away from the intrusions based on field measurements and analysis of photos from multiple angles to the outcrop. This regular spacing of the intrusions suggests instability at a preferred wavelength, which is a general feature of gravitationally unstable flows that will be discussed at length in subsequent sections.
[21] In summary, we infer from the geometry that the structures in Figure 2 are buoyant, ductile intrusion of the black rock into the overlying cataclasite. The black rock was less dense and less viscous than the cataclasite it intruded. The intrusion occurred simultaneously and at a similar strain rate to shear of the fault zone.

\subsection{Flame Structures: A Soft-Sediment Analog}

[22] The geometry of the black rock intrusions is similar to flame structures that are observed in soft sediment [Ronnlund, 1989; Visher and Cunningham, 1981]. The analogy is instructive and helps to support the inferred buoyant origin of the intrusions.

[23] We next briefly review the soft-sediment analog and its similarities to the rocks observed here.

[24] Flame structures are a somewhat rare but distinctive structure known from soft sediment deformation [Allen, 1982]. They occur in restricted localities where sand overlies mud along a sharp contact as in turbidites and a detailed description is given by Allen [1985]. The flame structures are the upward injections of mud into the sand layer that are generally found only on a restricted portion of an interface [Dasgupta, 1998].

[25] The structures have been attributed to an instability of the sediments by many authors [Allen, 1982; Anketell et al., 1970; Brodzikowski and Haluszczak, 1987; Collinson, 1994; Kelling and Walton, 1957; Lowe, 1975; Maltman, 1994; Owen, 1987, 1996]. Most work suggests that the instability is gravitational because of an inverse gradation in bulk density [Allen, 1982; Collinson, 1994; Kelling and Walton, 1957; Lowe, 1975; Maltman, 1994; Owen, 1996]. The gravitational model that interprets the flames as buoyant intrusions best explains the experimental data and natural occurrence.

[26] Morphologically, flames show many characteristic features that require a viscous, two-fluid origin. Intrusion of mud is always perpendicular to layering, i.e., upward. The peaks of the flame structures have a characteristic spacing and are concave-upward, pinching out at some height.

[27] As the prevalence of planar-bedded turbidites demonstrates, the instability occurs only under special circumstances when liquefaction is triggered by an external event, e.g., vibration from the passage of turbidity currents [Allen, 1982] or shaking from earthquakes [Bhattacharya and Bandyopadhyay, 1998; Horváth et al., 2005]. It is common for flame structures to occur over only a limited area even when bedding surfaces continue over a greater extent [Dasgupta, 1998].

[28] In an example from the Carmelo Formation turbidites at Pt. Lobos in central California, USA, flame structures formed by upward injection of lighter, low-density mud into higher-density sands (Figure 3; for a detailed description of the sedimentological context see Clifton [1984] and Dasgupta [1998]). Figure 3 illustrates the main features that characterize the gravitational instability in soft sediments:

[29] 1. Intrusions occur within essentially flat-lying layers (perpendicular to gravity) [Allen, 1985].

[30] 2. Intrusions narrow from base to peak.

[31] 3. Layers are (originally) roughly planar, base of source layer remains smooth after intrusions form. In the particular case of Figure 3, the bottom of the unit is wavy because of the 


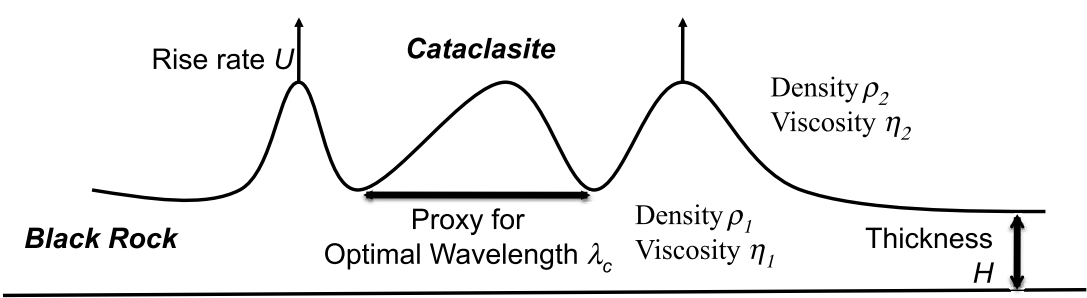

Figure 4. Geometry of the Rayleigh-Taylor problem. The densities $\rho_{1}$ and $\rho_{2}$ and viscosities $\eta_{1}$ and $\eta_{2}$ are of the lower and upper layers, respectively. The intrusions rise with a vertical velocity $U$.

sedimentary deformation of the layer below it, but this waviness is unrelated to the flame structure formation.

[32] 4. The lower density layer is overlain by a higherdensity layer [Anketell et al., 1970].

[33] 5. If intrusions are deflected, the direction of deflection is consistent [Anketell and Dzulynski, 1968; Potter and Pettijohn, 1977].

[34] 6. Intrusion shape or size is not systematically limited by rigid structure in denser layer; denser layer flows to accommodate intrusions from less-dense layer.

[35] 7. Intrusions have a characteristic spacing [Allen, 1985].

\subsection{Comparison of Fault Rock Intrusions and Soft-Sediment Structures}

[36] All seven of the criteria established above for soft sediment instabilities are met by the black rocks in the fault in Figure 2. The most striking difference is that the interval between intrusions is much shorter relative to the layer thickness in the fault rock case. We will return to this observation in the flow analysis below.

[37] In other places on the fault zone, the black rocks occur beneath consolidated metasandstone in the hanging wall rather than cataclasite (Figure 1). These sandstones were brittle at the conditions of deformation of the paleodecollement. The black rock injects into the sandstones but the style and scale are distinct from the flame structures case. These outcrops form a useful counterpoint that elucidates the behavior of a viscous, low-density fluid layer when the denser hanging wall is brittle rather than viscous. The injections of ultrafine-grained material into the sandstone satisfy the first three criteria above: layered structure, lower density material below, and (probably) near constant thickness in the black rock layer. However, characteristics of the sandstone-bounded intrusions violate the other four criteria. The injection orientation and spacing are consistent with activation of pre-existing joint patterns in the sandstone hanging wall. The outcrop where black rock underlies a solid sandstone hanging wall does not at all resemble sedimentary Raleigh-Taylor instabilities, while the outcrop where black rock underlies granular fault rocks closely resembles it. Flame structure morphologies develop only where both materials behave ductilely at the strain rate of deformation.

\section{Fluid Dynamics of the Rayleigh-Taylor Instability}

[38] The asymmetrical intrusions, like previously documented flame structures, imply that the driving force of the flow is a density instability that can be used to analyze the vertical motion of the black rock. The intrusion of a lowdensity layer into an overlying high-density layer is a wellstudied phenomenon known as a Rayleigh-Taylor instability [Turcotte and Schubert, 2002]. When the density of the lower layer, $\rho_{1}$, is less than that of the upper layer, $\rho_{2}$, the system is unstable and the lighter, black rock will intrude into the cataclasite (Figure 4). The buoyancy forces are balanced by viscous stress and the inertia of the fluid.

[39] The vertical velocity, $U$, of the intrusions varies with the wavelength. Linear stability analysis shows that there is generally an optimal wavelength, $\lambda_{\mathrm{c}}$, that grows fastest and thus dominates the resulting structure [Chandrasekhar, 1961; Conrad and Molnar, 1997; Turcotte and Schubert, 2002]. The linear stability analysis prediction of the optimal wavelength is consistent with physical laboratory experiments where the spacing between intrusions is interpreted as the optimal wavelength [Berner et al., 1972; Wilcock and Whitehead, 1991]. If shearing is simultaneous, the intrusions will be inclined relative to the vertical; this horizontal motion is independent of the buoyant growth that determines $\lambda_{c}$.

[40] We numerically solve for the growth rate $\gamma=U / H$ as a function of wavelength for a viscous fluid of thickness $H$ overlain by a layer of denser viscous fluid for a variety of geometries and rheologies as will be described below (Figures 5-10). Success of the model will be measured by the consistency of the computed optimal wavelength $\lambda_{c}$ with the observed spacing between black rock intrusions. The spacing of the observed structures is used as a proxy for optimal wavelength [Johnson and Fletcher, 1994]. As reported in the Observations section, the spacing for the Kodiak Island black rocks is $4.7 \pm 1.5 \mathrm{~cm}$ and the layer thickness is $3.5 \pm 0.6 \mathrm{~cm}$. Therefore the observed ratio $\lambda_{c} / H$ is $1.4 \pm 0.5$ (vertical gray line in Figure 5 with horizontal error bars) (Division of the mean values was performed with one additional significant digit than the final answer as is required for intermediate computations. As a result, the rounded value of the ratio is 1.4 rather than $4.7 / 3.5=$ 1.3.). If the peak of the growth rate curve as a function of wavelength coincides with the observed value of $\lambda_{\mathrm{c}} / H$ within the error range, the model will be interpreted as successful. We will begin with a basic model and add successive complications until we match the data.

\subsection{Noninertial Flows}

[41] We start with a configuration in which the top layer is infinite and has the same viscosity as the lower layer. For this first simple example, the viscosity of both layers is the same, the fluids are Newtonian and inertia is assumed to be 

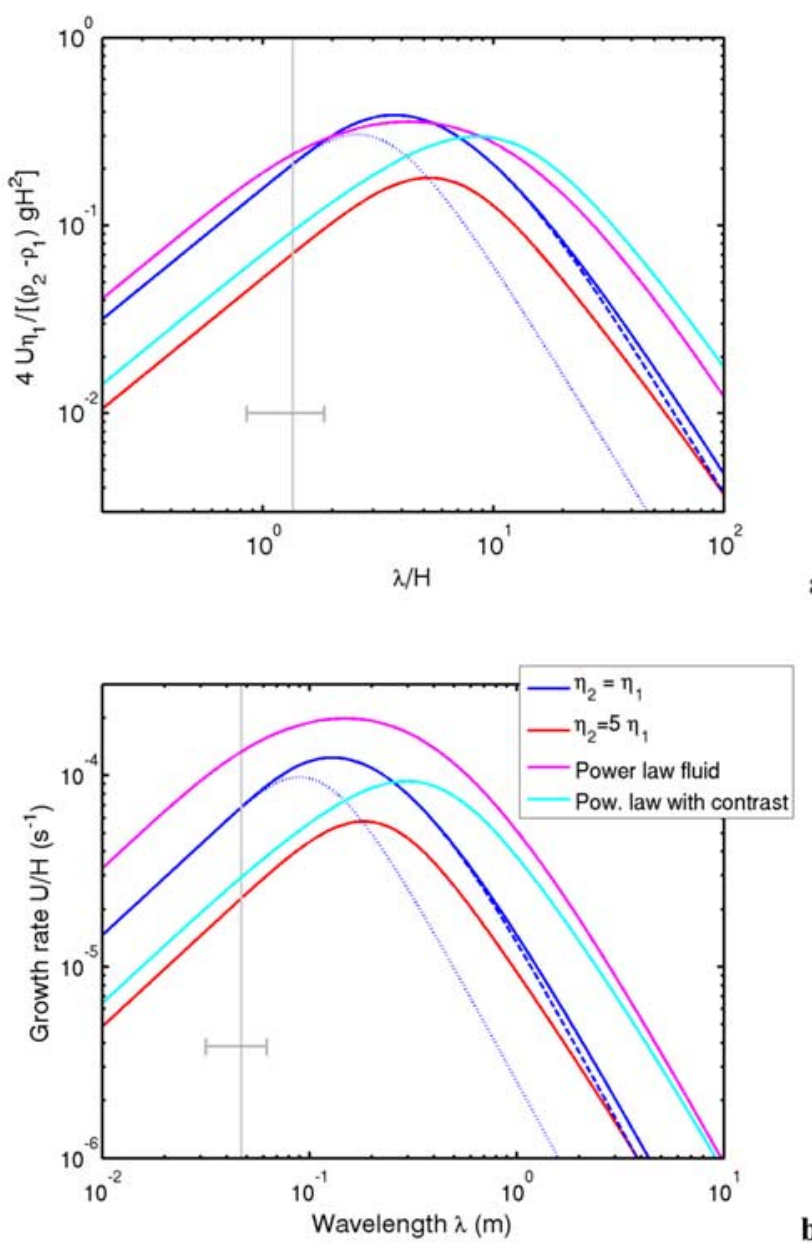

Figure 5. Growth rate of the instability as a function of wavelength for viscous (low Reynolds number) flows. (a) Dimensionless and (b) dimensional results shown for each case. Calculations are done with $H=0.035 \mathrm{~m}, \rho_{1}=$ $2685 \mathrm{~kg} / \mathrm{m}^{3}, \rho_{2}=1.014 \rho_{1}$, and $\eta_{1}=10^{4} \mathrm{~Pa} \mathrm{~s}$. For the power law fluid with no contrast, $\eta_{0}=10^{4} \mathrm{~Pa}^{\mathrm{n}} \mathrm{s}$ and $n=5$ and for the contrast case, $\eta_{0}=10^{4} \mathrm{~Pa}^{\mathrm{n}} \mathrm{s}$ and $n=1.5$ in the black rock and $\eta_{0}=5 \times 10^{4} \mathrm{~Pa}^{\mathrm{n}} \mathrm{s}$ and $n=5$ in the cataclasite. As discussed in the text, the blue solid line in Figure $5 \mathrm{a}$ is nondimensionalized to be independent of these material properties as long as inertia is negligible. The dotted and dashed lines are for two layers of finite thickness and equal viscosity. The top layer is the same thickness as the bottom for the dotted line $(0.035 \mathrm{~m})$ and is $0.3 \mathrm{~m}$ (the observed thickness of the textural domain in the cataclasite) for the dashed line. The gravitational acceleration $g$ is $9.8 \mathrm{~m} / \mathrm{s}^{2}$. None of the modeled curves shown successfully match the data.

negligible. The boundary conditions for this and all subsequent calculations are no-slip at the top and bottom of the system (Appendix A). As the gravitational instability is inherently asymmetric with no flow downwards, a zero velocity boundary condition on the vertical velocity is appropriate at the base of the low-density layer. Figure 5 shows the results in both dimensionless form and with units appropriate for the Kodiak Island black rock. For the singleviscosity case, a single dimensionless curve completely describes the solution (dark blue solid curve) [Turcotte and Schubert, 2002]. The most unstable wavelength $\lambda_{\mathrm{c}}=$ 3.7 $\mathrm{H}$, which is inconsistent with the observed range. Note that $\lambda_{c} / H$ is independent of viscosity and density. Making the top layer finite (dotted and dashed lines) does not significantly change the value of $\lambda_{c} / H$.

[42] A more realistic model incorporates the viscosity contrast between the black rock and the cataclasite. As discussed above, the black rock is more stretched and cuspate than the cataclasite and therefore we infer that the black rock is the less viscous of the two layers. Incorporating this complication increases the value $\lambda_{c} / H$ as shown by the red curve in Figure 5. Therefore the contrast in viscosity results in modeled optimal wavelengths even further from observed spacing than in the single-viscosity case.

[43] In a further effort to match the observations, we add the complication of a non-Newtonian rheology. We model both the black rock and the cataclasite as power law fluids where the strain rate is proportional to shear stress to the
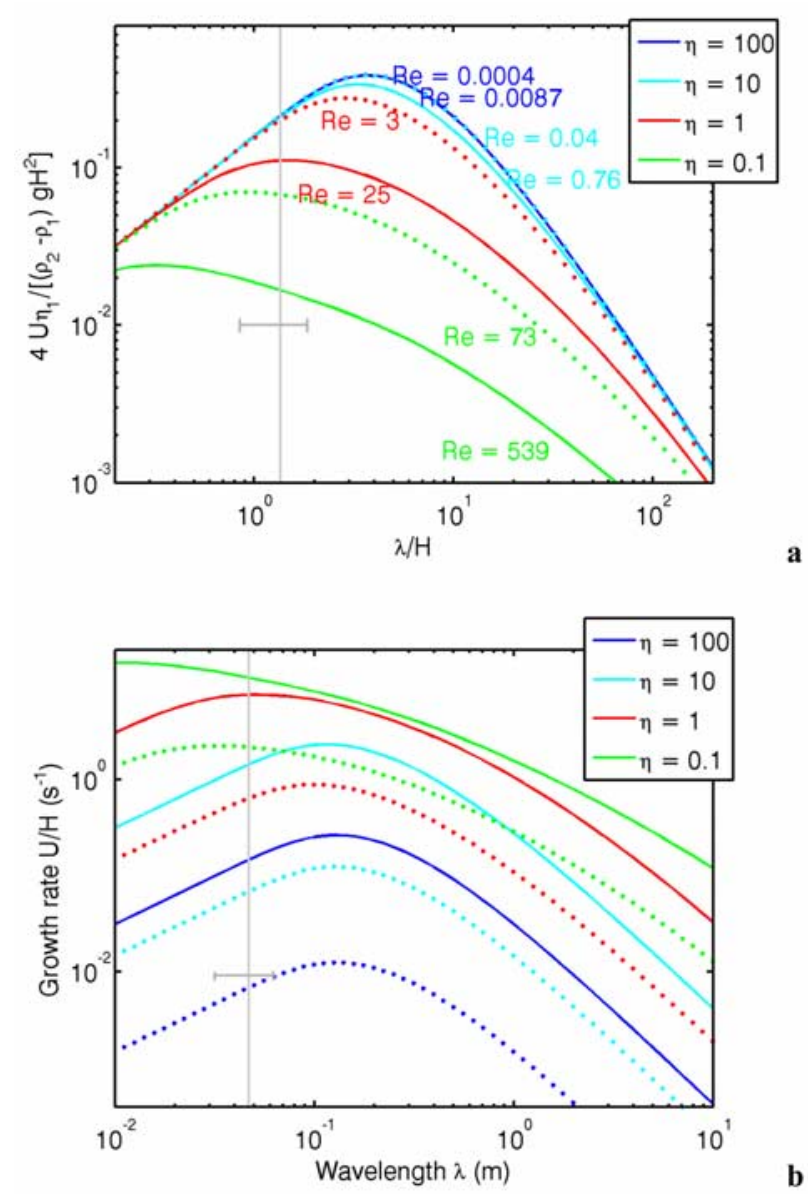

Figure 6. Growth rate of the instability as a function of wavelength for a variety of Reynolds numbers. (a) Dimensionless and (b) dimensional results for identical viscosity in both layers. Plus symbols are a density contrast of $1.4 \%$ and solid lines are $30 \%$ for each case. As in Figure 5 , the thickness of the bottom layer is $0.035 \mathrm{~m}$, the top layer is infinite, and $\rho_{1}=2685 \mathrm{~kg} / \mathrm{m}^{3}$. The Reynolds numbers $R e$ are given for the most unstable wavelength of each curve. 

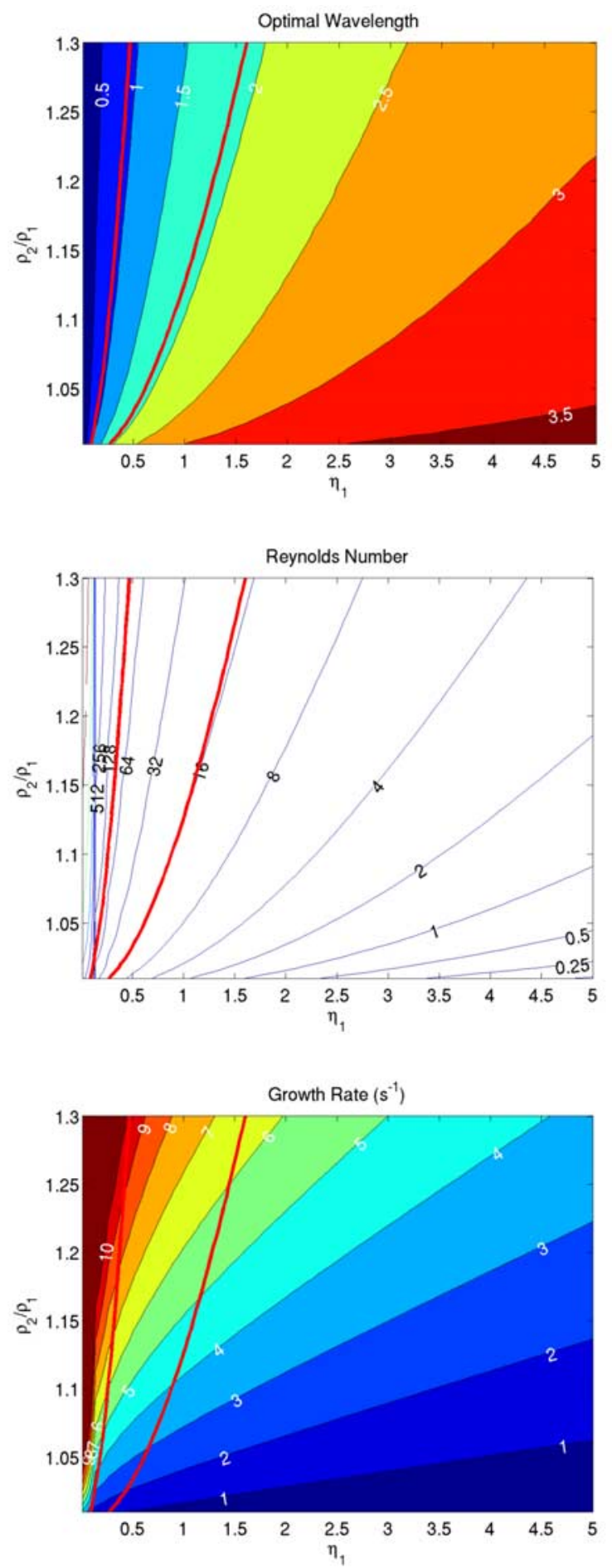

Figure 7. Contours of the model results as a function of density ratio and viscosity for single-viscosity models with nonnegligible inertia. (a) Optimal wavelength corresponding to the peak growth rate. Wavelength is normalized by the layer thickness $(0.035 \mathrm{~m})$ and is therefore dimensionless. (b) Reynolds numbers. (c) Growth rates. Thick red lines outline the region with optimal wavelength consistent with the observed range of intrusion spacing (wavelength to thickness ratio $=0.9-1.9$ ). Reynolds number contours in Figure $7 \mathrm{~b}$ are by factors of 2 , with the 4 highest contours on the plot unlabeled to prevent overlapping numbers.

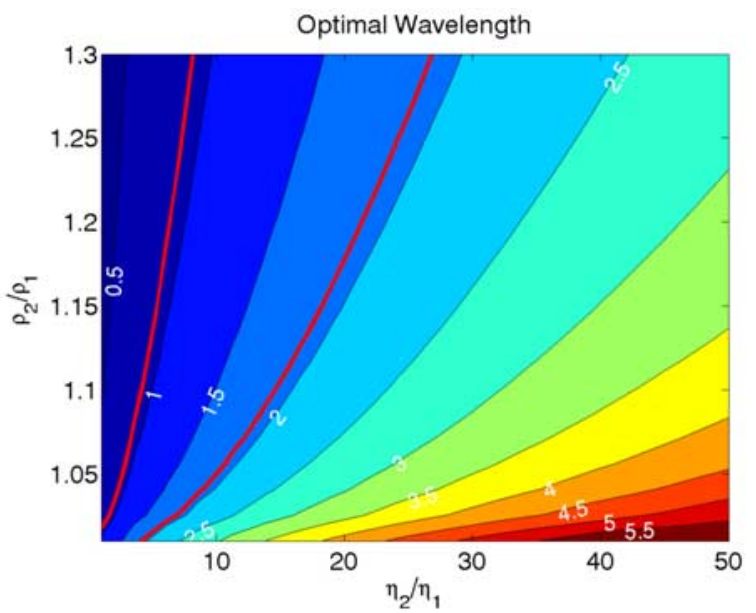

a

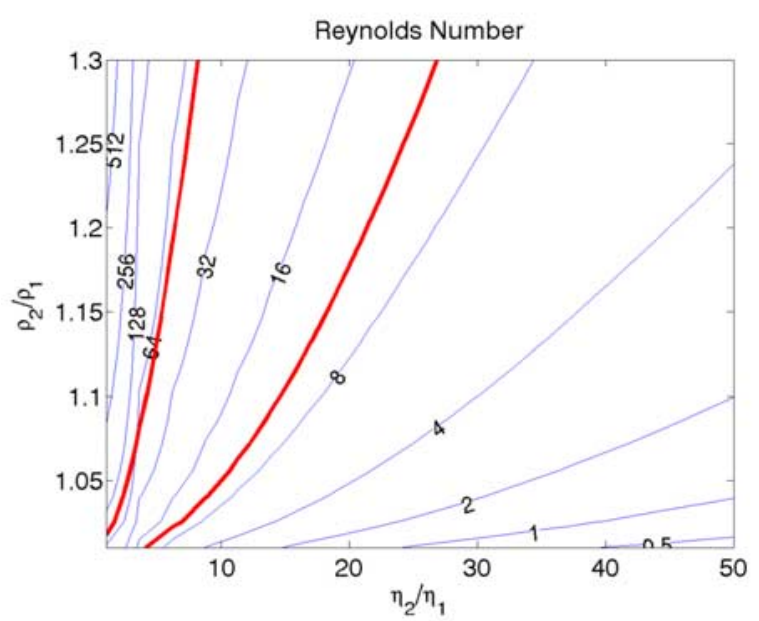

b

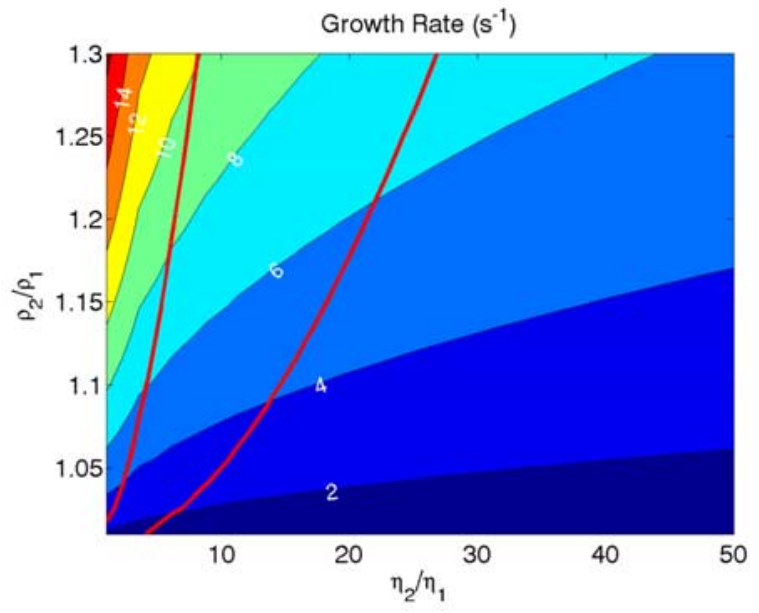

Figure 8. Contours of the model results as a function of viscosity ratio and density ratio for fixed values of viscosity in the black rock layer of $0.1 \mathrm{~Pa}$ s. (a) Optimal wavelength corresponding to the peak growth rate. Wavelength is normalized by the layer thickness $(0.035 \mathrm{~m})$ and is therefore dimensionless. (b) Reynolds numbers in the cataclasite. (c) Growth rates. Thick red lines outline the region with optimal wavelength consistent with the observed range of intrusion spacing $(0.9-1.9)$. 

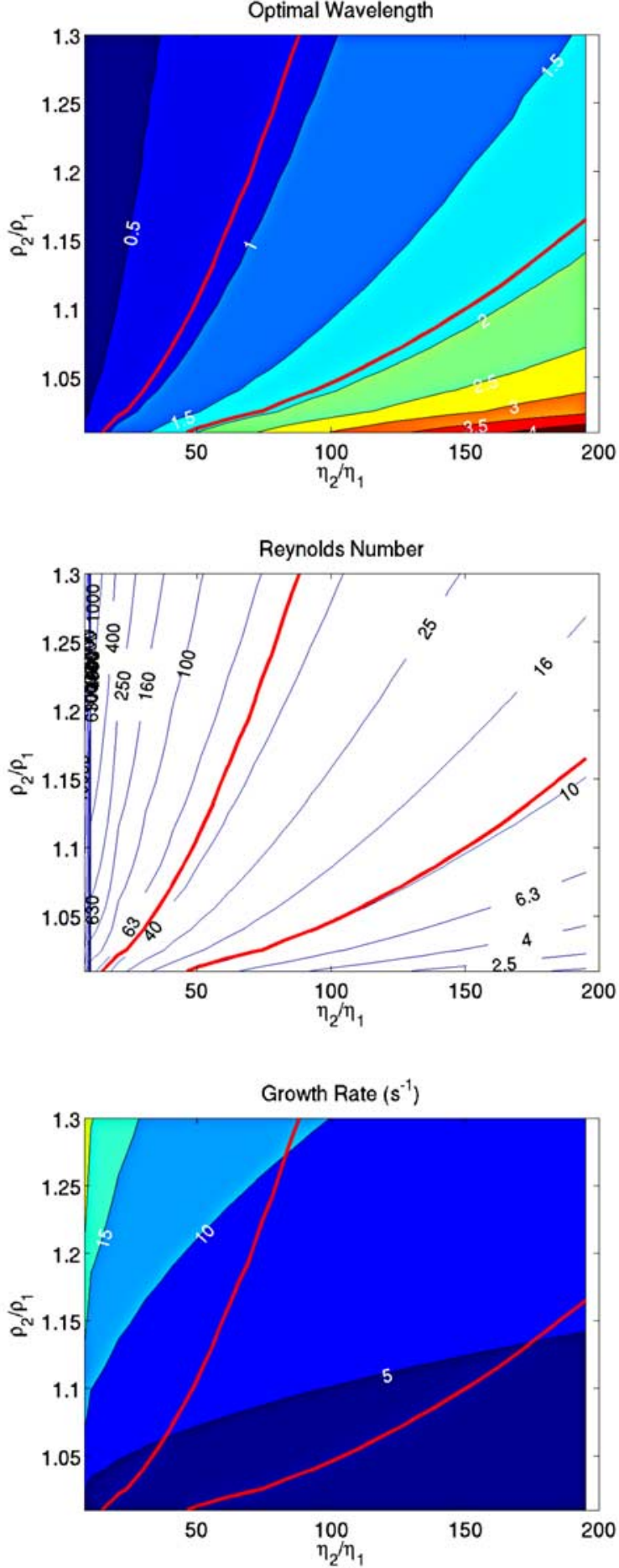

Figure 9. Contours of model results for a smaller value of the black rock viscosity of $0.01 \mathrm{~Pa}$ s. (a) Optimal wavelength corresponding to the peak growth rate. Wavelength is normalized by the layer thickness $(0.035$ $\mathrm{m}$ ) and is therefore dimensionless. (b) Reynolds numbers in the cataclasite. (c) Growth rates. Thick red lines outline the region with optimal wavelength consistent with the observed range of intrusion spacing (0.9-1.9). power of $n$ ( $n=1$ for a Newtonian fluid) using a modification of a standard analysis for folding and boudinage [Smith, 1977] (Appendix A). In this rheology, the effective viscosity at a given strain rate $\gamma$ is $\eta_{0}^{1 / \mathrm{n}} \gamma^{(1 / \mathrm{n})-1}$ where $\eta_{0}$ is a constant. Magma can have $n=1.5$ and solid state rocks can have $n=2-5$. Figure 5 shows the most extreme case with $n=5$ in both layers as the pink curve [Sonder et al., 2006; Twiss and Moores, 1992]. The wavelength of the maximum growth is nearly unaffected by the rheology $\left(\lambda_{c} / H=4.3\right)$. Nondimensionalizing as before with $\eta_{1}$ equal to the effective viscosity at the peak growth rate results in a broader peak with the nondimensional maximum growth consistent with the Newtonian model (Figure 5a). We also investigate a difference in power law exponents in the top and bottom layers. As in the Newtonian case, if the effective viscosity of the upper layer is higher (as required by the data), then the value of $\lambda_{c} / H$ increases. Although only a few model cases are shown here, they illustrate that the trend of the non-Newtonian effect runs counter to that required by the data.

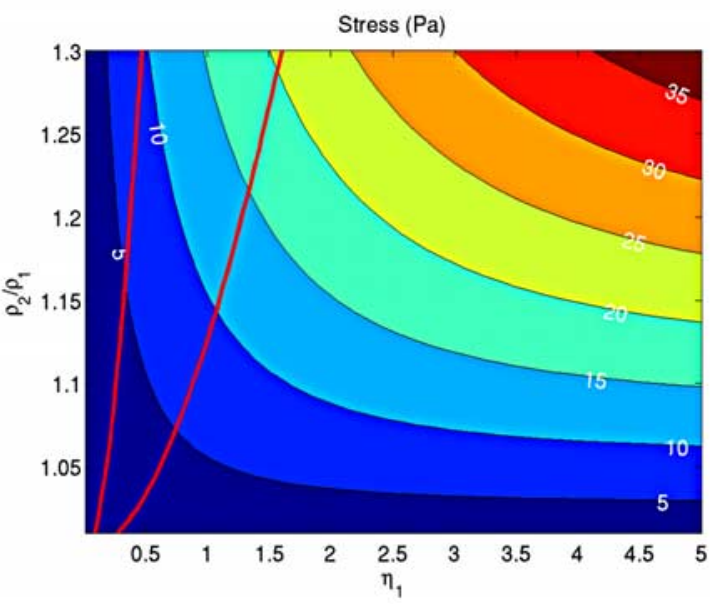

a

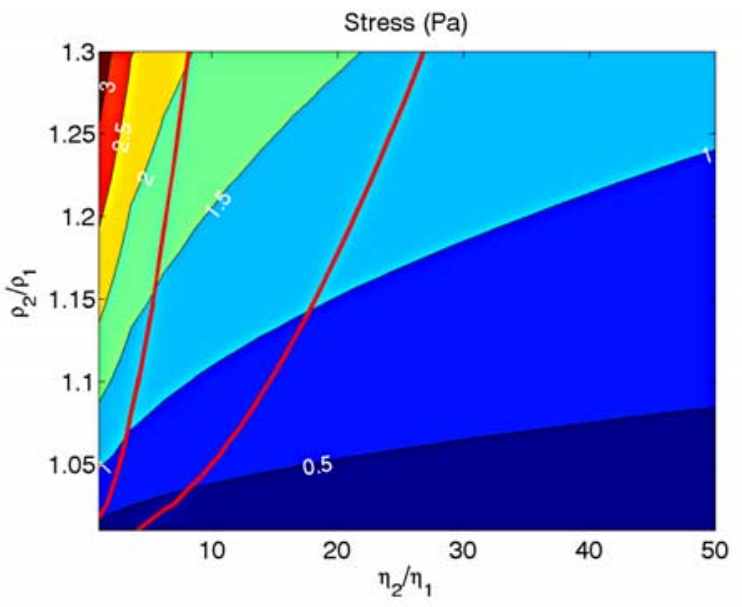

b

Figure 10. Viscous stress in the lower layer (black rock) assuming that the horizontal strain rate is the same as the vertical (see text). (a) Single-viscosity model corresponding to Figure 7. (b) Dual viscosity model with lower layer viscosity of $0.1 \mathrm{~Pa}$ s corresponding to Figure 8 . 
[44] In summary, the model results thus far show that the real system has a spacing between intrusions that is much shorter than can be explained easily by a Rayleigh-Taylor instability model without inertia. This result holds true even if we consider a finite thickness of the upper layer, a viscosity contrast between the layers or a non-Newtonian rheology. Therefore we conclude that the noninertial model is a poor fit to the observed structures.

\subsection{Inertial Flows}

[45] Inertial flows have a broader spectrum of unstable wavelengths and the most unstable value is smaller than in the purely viscous case. Using the theory of Chandrasekhar [1961] and Mikaelian [1996], we repeat the calculation of growth rate as a function of wavelength for parameter ranges where the inertial effects are significant (Figure 6). The Reynolds number, $R e$, measures the relative strength of the inertial and viscous effects. For the present problem, $R e=U H \rho_{2} / \eta_{2}$ where the subscript of 2 indicates the values in the upper layer and Re values greater than 1 indicate that inertia is important. Since the values of $H$ and $\rho$ are constrained by the observations and $U$ is computed by the flow calculations, the most straightforward way to adjust the Reynolds number of the modeled flow is to manipulate the viscosity.

[46] As in the noninertial case, we begin the modeling exercise with the unrealistic, but simple assumption that both layers have the same Newtonian viscosity (Figures 6a and 6b). In the examples shown, flows with moderate Reynolds numbers like 25 and 73 have peak growth rates at wavelengths consistent with the observations for the range of plausible densities (Figures 6a and 6b). This result is reinforced by an exploration of optimal wavelength as a function of density contrast and viscosity in Figure $7 \mathrm{a}$. The contours of optimal wavelength track the contours of Reynolds number in the cataclasite (Figure 7b). The stiffer, thicker layer limits the spacing between intrusions. The flows with moderate Reynolds numbers of 16-86 have optimal wavelengths within the observational range marked by the thick red curves. This range corresponds to a restricted range of growth rates of $1-10 \mathrm{~s}^{-1}$ (Figure 7c).

[47] As in the noninertial case, incorporating the observed viscosity contrast increases the optimal wavelength for a given density contrast and black rock viscosity. The tradeoff between viscosity contrast and density contrast is mapped out in Figure 8 for a fixed lower layer (black rock) viscosity of $0.1 \mathrm{~Pa} \mathrm{~s}$ as an example. The Reynolds number in the upper layer (cataclasite) is still a good predictor of the optimal wavelength (Figures $8 \mathrm{a}$ and $8 \mathrm{~b}$ ). Flows that match the data have Reynolds numbers of 10-51.

[48] The growth rate of the intrusions is also constrained by the flow model and the observed data. For the range of acceptable density contrasts with viscosity ratios corresponding to the upper layer Reynolds number of $10-$ 51 , the growth rates are $1-10 \mathrm{~s}^{-1}$ (Figure $8 \mathrm{c}$ ). This result is only weakly sensitive to the viscosity in the lower layer as illustrated by Figure 9. Here the lower layer viscosity is fixed an order of magnitude smaller than in the previous example, and the Reynolds number range and growth rate range matching the data is nearly the same $(\mathrm{Re}=10-49$, growth rate $=1-10 \mathrm{~s}^{-1}$ ).
[49] The strain rate multiplied by the thickness of the black rock layer $H$ is the vertical rise velocity at the onset of the instability. For $H=0.035 \mathrm{~m}$, the initial rise velocity corresponding to Figures $7-9$ is therefore $0.04-0.4 \mathrm{~m} / \mathrm{s}$, depending on the viscosity conditions. The horizontal shear rate and vertical growth rate are comparable, so the structures were generated at a slip rate of $10 \mathrm{~s}$ of $\mathrm{cm} / \mathrm{s}$, which is typical of an earthquake or immediately after. Thus the black rock was mobilized during an earthquake. The fluidization could have occurred by a variety of processes including melting, elevated pore pressure or intergranular collision [Bagnold, 1956; Otsuki et al., 2003]. The exposure preserves the structures solidified after the generation of the fluid and thus represents the last stages of the earthquake slip. Once fluidized, it moved rapidly and buoyantly intruded the overlying cataclasite at a moderate Reynolds number.

[50] The viscous shear stress in a fluid layer is twice the product of the strain rate and viscosity (Figure 10). Here we use the inference that the shear strain rate in the black rock is similar to the growth rate of the rising instabilities. The growth rate is well-constrained as $1-10 \mathrm{~s}^{-1}$ by the intrusion spacing data, but the lower layer viscosity is only weakly constrained. The most certain inference is that the lower layer (black rock) has a lower effective viscosity than the upper layer (cataclasite). The maximum value of the upper layer viscosity is provided by the single-viscosity case. The highest viscosity that results in sufficient inertia (Reynolds number) to match the data is $1.5 \mathrm{~Pa} \mathrm{~s}$ (Figure 7a) and the corresponding stress is $20 \mathrm{~Pa}$ (Figure 10a). Therefore the maximum bound of the viscous stress in the lower layer (black rock) is $20 \mathrm{~Pa}$.

\section{Origin of the Black Rock}

[51] Having constrained the viscosity of the black rock, we can now use it to evaluate the candidate origins of the black rock. Pseudotachylytes (frictionally-induced melts) are one of few established features used to infer rapid slip from geologic data [Biegel and Sammis, 2004; Cowan, 1999; Di Toro et al., 2005; Magloughlin, 1992; Sibson and Toy, 2006]. However, pseudotachylytes are apparently rare and their identification is difficult [Otsuki et al., 2003; Sibson and Toy, 2006; Ujiie et al., 2007a]. We can calculate the required temperature for a melt of the observed composition, pressure and fluid conditions to achieve the geometrically constrained viscosity. Should the inferred temperature be plausible, then pseudotachylytes are a permissible mechanism.

[52] The high pressure and water content of the accretionary prism permits fully saturated melts of unusually high water contents. The black rock composition is equivalent to a high silica andesite (Table B1). At $380 \mathrm{MPa}$ $(13 \mathrm{~km})$ and $1400^{\circ} \mathrm{C}$, a melt of the composition of the black rock is fully saturated with $6.6 \mathrm{wt} \%$ water and has a viscosity of $1 \mathrm{~Pa} \mathrm{~s}$ (Appendix B). A pseudotachylyte at these conditions is consistent with the spacing constraint of the intrusions. Such a high temperature is also consistent with the minimum bound of $1100^{\circ} \mathrm{C}$ imposed by the rarity of feldspar survivor grains in the black rock [Rowe et al., 2005]. The inferred temperature and water content is consistent with that inferred for fault slurries with local 
Table 2. Parameters for Energy Balance Calculations $(\text { Equation (1) })^{\mathrm{a}}$

\begin{tabular}{ll}
\hline \multicolumn{1}{c}{ Parameter } & \multicolumn{1}{c}{ Value } \\
\hline Specific heat capacity $c_{p}$ & $4 \times 10^{3} \mathrm{~J} /{ }^{\circ} \mathrm{C} \mathrm{kg}$ \\
Thickness of black rock $h$ & $0.029-0.041 \mathrm{~m}$ \\
Density of black rock $\rho$ & $2700 \mathrm{~kg} / \mathrm{m}^{3}$ \\
Latent heat $L$ & $0.3 \mathrm{MPa}$ \\
Coefficient of friction & $0.2-0.6$ \\
Lithostatic Pressure $P_{L}$ & $320-380 \mathrm{MPa}$ \\
Slip $D$ & $5-10 \mathrm{~m}$ \\
\hline
\end{tabular}

${ }^{\text {a }}$ Specific heat and latent heat are from Turcotte and Schubert [2002]. The thickness range of the black rock encompasses 1 standard deviation of measurements. The range of coefficient of frictions spans current highspeed laboratory values through typical Byerlee Law values [Byerlee, 1970; Yuan and Prakash, 2008]. The density of the black rock is rounded from Table 1. Lithostatic pressure is calculated for $12-14 \mathrm{~km}$. Slip is a typical range during a single large earthquake $\left(M_{\mathrm{w}} 7.5-8.5\right)$.

melting observed in the Nojima fault and similar to the Shimanto accretionary complex [Otsuki et al., 2003; Ujiie et al., 2007b].

[53] Lower viscosities of the melt are also permissible in the flow model, but require extraordinarily high temperatures. A viscosity of $0.1 \mathrm{~Pa}$ s corresponds to a temperature of $1900^{\circ} \mathrm{C}$ fully saturated at the same pressure conditions as above.

[54] High temperatures can be generated by the frictional heat of the fault during a large earthquake in part because of the great depth of the fault implies an unusually high frictional heat. The pre-slip temperature of the fault based on fluid inclusions is $270^{\circ} \mathrm{C}$, thus a temperature increase of at least $1130^{\circ} \mathrm{C}$ is necessary to satisfy the petrologic constraints [Vrolijk et al., 1988]. A naïve calculation of the temperature increase in a melt during the earthquake balances the excess temperature and latent heat with the frictional heat generated.

$$
\Delta T c_{p} h \rho+L h \rho=\mu P_{L} D
$$

where $\Delta T$ is the temperature increase over the preseismic temperature, $c_{p}$ is the specific heat capacity, $h$ is the thickness of the melt zone, $\rho$ is the density of the melt, $L$ is the latent heat, $\mu$ is the coefficient of friction, $P_{L}$ is the lithostatic pressure and $D$ is the slip. Using the parameters in Table 2, equation (1) results in a range of temperature increases of $600-7000^{\circ} \mathrm{C}$. As pointed out by Fialko and Khazan [2005], this simplistic calculation overestimates the heat produced as the shear resistance drops dramatically on the wetted surface once melting begins. The calculation only demonstrates that in a system with some areas in solid contact ample energy is available for the elevated temperatures implied by the rheology.

[55] Another possible origin of the fault rock is as a fluidized granular flow where either an aqueous fluid is sufficiently pressurized to support the matrix or the inertial collisions of the grains maintains a non-Newtonian viscosity [Rowe et al., 2005; Ujiie et al., 2007a]. Unfortunately, comparable constraints on the physical conditions of a fluidized granular flow are not possible as the rheology has never been investigated at the appropriate pressure, temperature and speeds. The little experimental data that exists at atmospheric pressure on laboratory debris flows reports that mobilized slurries at strain rates $>5 \mathrm{~s}^{-1}$ and sediment volume concentrations of $40-70 \%$ have effective viscosities of $\sim 1-10 \mathrm{~Pa}$ s [Major and Pierson, 1992]. The lower bound of this viscosity range is consistent with the rheological constraints here.

[56] We therefore conclude that either the fluidized slurry or the extremely high-temperature $\left(\geq 1400^{\circ} \mathrm{C}\right)$ melt are consistent with the rheological constraints on the black rock. The geometry may not help resolve the question of the origin of the black rocks, but the consistency with plausible regimes in both cases helps bolster the RayleighTaylor interpretation of the flow.

\section{Summary and Conclusions}

[57] The extremely short spacing of the intrusions observed on the exhumed Kodiak Island megathrust indicate that the black fault core rocks represent a very low viscosity ( $\leq 1 \mathrm{~Pa}$ s) fluid emplaced during an earthquake. This conclusion is based on the geometry of the intrusive structures and supported by measurements of the densities of the units. No prior knowledge of the origin of the fault rock is necessary.

[58] Although the buoyant intrusive features are only formed where the overlying cataclasite is fluid enough to accommodate ductile intrusions, the black rock persists over $2.5 \mathrm{~km}$ of strike-parallel exposure. Elsewhere on the fault, direct contact between the wall rocks may have resulted in high shear stresses, but were the black rock is present the fault was lubricated with a fluid that supported little shear $(<20 \mathrm{~Pa})$.

[59] The rock record has provided an example of extreme fault weakening that easily satisfies geophysical constraints suggesting low friction as well as petrological constraints on the material properties of a silicate melt or granular flow. The picture that begins to emerge is a fault zone controlled by multiphase processes including local, extraordinarily weak zones of low-viscosity fault fluids flowing rapidly during an earthquake.

\section{Appendix A: Linear Stability Analysis}

[60] The main text solves four closely related linear stability problems: the buoyant intrusion of a Newtonian fluid into another Newtonian fluid for both finite and infinite overlying layers, the buoyant intrusion of a power law fluid into another power law fluid and the buoyant intrusion of a Newtonian fluid into an infinite Newtonian fluid with inertia. All of the Newtonian fluid configurations have either been solved in the literature or require only minor modifications of existing solutions. The power law fluid case requires a more significant modification.

[61] The general solution method is outlined below. Here we primarily follow the notation of Smith [1977] who studied the closely related problem of viscous folding. For a Newtonian fluid with negligible inertia, combining the momentum and continuity equations results in the biharmonic equation

$$
\nabla^{4} \psi=0
$$

where $\psi$ is the stream function. The velocity field of the fluid is $u=\frac{\partial \psi}{\partial y}$ and $v=-\frac{\partial \psi}{\partial x}$ where $v$ is the flow velocity in the $x$ direction and $u$ is the flow velocity in the $y$ direction. 
The shear measurements indicate that vertical growth rate $u$ is comparable to horizontal shear rate $v$, establishing a basis for control on $v$. The linear stability of the system is investigated by assuming a separable solution to $\psi$ of the form $\psi(x, y, t)=\varphi(y) \exp [$ iax $] \exp [\gamma t]$ where $\varphi(y)$ is an appropriate function of $y, \gamma$ is the growth rate, the wavenumber $a=2 \pi / \lambda$ and $\lambda$ is the wavelength. The growth rate is in units of strain rate, i.e., 1/time. Surface tension is neglected.

[62] Substituting $\psi$ into equation (A1) results in

$$
\varphi^{\prime \prime \prime \prime}-2 a^{2} \varphi^{\prime \prime}+a^{4} \varphi=0
$$

$$
M=\left[\begin{array}{ccc}
1 & 0 & 1 \\
-a & 1 & a \\
-e^{-a h} & -e^{-a h} h & -e^{a h} \\
a e^{-a h} & e^{-a h}(a h-1) & -a e^{a h} \\
2 a^{2} e^{-a h} m & 2 a e^{-a h}(a h-1) m & 2 a^{2} e^{a h} m \\
2 a^{3} e^{-a h} m & 2 a^{3} e^{-a h} h m & -2 a^{3} e^{a h} m
\end{array}\right.
$$

-

[64] The no slip condition at the bottom of the lower boundary is achieved at $y=0$ with the equations

$$
\begin{aligned}
& \varphi_{1}=0 \\
& \varphi_{1}^{\prime}=0
\end{aligned}
$$

[65] The solution for the growth rate $\gamma$ as a function of wavenumber $a$ is found by posing the boundary conditions as a matrix system $M G=0$ where $G$ is the vector of constant coefficients ( $A, B, C$ and $D$ for each layer). For instance, for the case of an infinite top layer, the matrix is

$$
\left.\begin{array}{ccc}
0 & 0 & 0 \\
1 & 0 & 0 \\
-e^{a h} h & e^{-a h} & e^{-a h} h \\
e^{a h}(1+a h) & -a e^{-a h} & e^{-a h}(1-a h) \\
e^{a h}(1+a h) m & -2 a^{2} e^{-a h} & -2 a e^{-a h}(a h-1) \\
-2 a^{3} e^{a h} h m & \frac{a^{2} e^{-a h}\left(\Delta \rho g-2 a \gamma \eta_{1}\right)}{\gamma \eta_{1}} & \frac{a^{2} e^{-a h} h\left(\Delta \rho g-2 a \gamma \eta_{1}\right)}{\gamma \eta_{1}}
\end{array}\right]
$$

where primes are derivatives with respect to $y$. The boundary conditions can also be posed in terms of $\varphi$. The coordinate system is chosen such that the bottom of layer 1 is $y=0$. The thickness of layer 1 is $h$ and if the top layer is finite, the thickness of the two layers together is $h_{2}$. There is no slip and a continuity of traction between the layers, so the boundary conditions at $y=h$ are

$$
\begin{gathered}
\varphi_{1}=\varphi_{2} \\
\varphi_{1}^{\prime}=\varphi_{2}^{\prime} \\
\left(\varphi_{1}^{\prime \prime}+a^{2} \varphi_{1}\right)=m\left(\varphi_{2}^{\prime \prime}+a^{2} \varphi_{2}\right) \\
\left(\varphi_{1}^{\prime \prime \prime}-3 a^{2} \varphi_{1}\right)-m\left(\varphi_{2}^{\prime \prime \prime}-3 a^{2} \varphi_{2}\right)=-\Delta \rho g a^{2} \varphi_{1} / \gamma \eta_{1}
\end{gathered}
$$

where the subscripts 1 and 2 indicate the bottom and top layer, respectively, $\Delta \rho$ is the density difference between the top and bottom layer $\left(\rho_{2}-\rho_{1}\right), \eta_{1}$ is the viscosity of the bottom layer and $m$ is the ratio of the viscosities $\left(m=\eta_{2} / \eta_{1}\right)$. Note that the subscript convention is reversed from Smith [1977]. The last boundary condition equation (A6) comes from the stress equilibrium at the interface and incorporates buoyancy [Conrad and Molnar, 1997]. This term is the most important difference between the folding problem of Smith [1977] and the gravitational instability studied here.

[63] An appropriate form of $\varphi(y)$ that respects the boundary conditions must be chosen. For the Newtonian cases, $\varphi(y)=A \exp [a y]+B y \exp [a y]+C \exp [-a y]+D y$ $\exp [-a y]$. If the top layer is infinite, $A=B=0$ in that layer (layer 2). Otherwise, at the top of the layer $y=h_{2}$, no slip is achieved by

$$
\begin{aligned}
& \varphi_{2}=0 \\
& \varphi_{2}^{\prime}=0
\end{aligned}
$$

[66] Solving the equation $\operatorname{Det}(M)=0$ provides a solution for the growth rate $\gamma$ as a function of wavenumber $a$. We solve this equation numerically for every case although analytical solutions are possible for the simplest configurations studied here.

[67] For power law fluids the rheology is $\sigma^{n} \propto \dot{\varepsilon}$ where $\sigma$ and $\dot{\varepsilon}$ are the stress and strain rate tensors and $n$ is a material constant. Smith [1977] performs a perturbation on the rheology as well as the deformation field for a basic flow of horizontal compression or extension. He shows that the linear stability equations are similar to the Newtonian fluid case. We extend the analysis for a basic flow of simple shear. In this case, the equations are identical to the Newtonian fluid case except equation (A6) becomes

$$
\begin{aligned}
\left(\varphi_{1}^{\prime \prime \prime}-\right. & \left.\left(2 W_{1}+1\right) a^{2} \varphi_{1}^{\prime}\right)-m\left(\varphi_{2}^{\prime \prime \prime}-\left(2 W_{2}+1\right) a^{2} \varphi_{2}^{\prime}\right) \\
& =-n \Delta \rho g a^{2} \varphi_{1} / \gamma \eta_{1}
\end{aligned}
$$

where $W=2 n-1$ and the subscripts of 1 and 2 denote the bottom and top layers, respectively. In this case, the function $\varphi(y)=\sum_{i=1,4} A_{i} \exp \left[l_{i} y\right]$ where $l_{i}$ are the four values of $\pm a \sqrt{W \pm \sqrt{W^{2}-1}}$ for each layer [Smith, 1977]. [68] For the high Reynolds number case, the inertial term makes the right-hand side of equation (A1) nonzero and a stream function is no longer an appropriate tool for solving the problem. Chandrasekhar [1961] uses a similar method based on a perturbation expansion of the flow velocity rather than the stream function. He explores the case with negligible advection, but significant inertia from the local acceleration of the fluid. The eigenfunctions in this case include an inertial term [Chandrasekhar, 1961, section 94]. This method is used here with the modifications for a finite layer on the bottom introduced by Mikaelian [1996]. These theories only address the Newtonian fluid case.

\section{Appendix B: Melt Viscosity and Density Calculation}

[69] We calculated the viscosity of a silicate melt with the bulk composition measured from the black rock samples 
Table B1. Composition Kodiak Island Black Rock and Foliated Cataclasites $^{\text {a }}$

\begin{tabular}{lccccc}
\hline & \multicolumn{2}{c}{ Black Rock Weight \% } & & \multicolumn{2}{c}{ Cataclasite Weight \% } \\
\cline { 2 - 3 } \multicolumn{1}{c}{ Oxides } & Mean & $\begin{array}{c}\text { Standard } \\
\text { Deviation }\end{array}$ & & Mean & $\begin{array}{c}\text { Standard } \\
\text { Deviation }\end{array}$ \\
\hline $\mathrm{SiO}_{2}$ & 58.53 & 1.99 & 59.07 & 0.96 \\
$\mathrm{TiO}_{2}$ & 0.94 & 0.04 & 0.83 & 0.03 \\
$\mathrm{Al}_{2} \mathrm{O}_{3}$ & 17.80 & 0.63 & & 16.70 & 0.60 \\
$\mathrm{FeO}$ & 6.71 & 0.20 & 6.57 & 0.54 \\
$\mathrm{Fe}_{2} \mathrm{O}_{3}$ & 0.20 & 0.23 & 0.56 & 0.55 \\
$\mathrm{MnO}$ & 0.20 & 0.23 & 0.15 & 0.06 \\
$\mathrm{MgO}$ & 2.84 & 0.81 & 2.96 & 0.55 \\
$\mathrm{CaO}$ & 1.42 & 0.73 & & 1.77 & 0.79 \\
$\mathrm{Na}$ & 4.01 & 0.98 & 2.19 & 0.78 \\
$\mathrm{~K}_{2} \mathrm{O}$ & 1.60 & 1.01 & 2.45 & 0.88 \\
$\mathrm{P}_{2} \mathrm{O}_{5}$ & 0.25 & 0.02 & 0.24 & 0.04 \\
Lost on ignition & 4.95 & 0.45 & 4.78 & 0.37 \\
Total & 99.26 & & 99.39 & \\
\hline
\end{tabular}

${ }^{\mathrm{a}}$ Whole rock geochemical analyses of major and trace elements were determined by wavelength dispersive X-ray fluorescence (WD-XRF) analysis with a Philips PW2400 equipped with Rhodium tube (Department of Mineralogy and Petrology, University of Padova). For analysis, powder samples were mixed and diluted at $1: 10$ with $\mathrm{Li}_{2} \mathrm{~B}_{4} \mathrm{O}_{7}$ and $\mathrm{LiBO}_{2}$ flux and melted into glass beads. Loss on ignition (LOI) was determined from weight lost after ignition at $860^{\circ} \mathrm{C}$ for $20 \mathrm{~min}$ and at $980^{\circ} \mathrm{C}$ for $2 \mathrm{~h}$. $\mathrm{FeO}$ was determined with permanganometry using a Rhodium tube. International rock standards were used for calibration. Four samples were analyzed for the black rock and eight for the cataclasite.

(Table B1) using the program Conflow [Mastin and Ghioroso, 2000]. We renormalize the composition to $100 \%$ without the loss on ignition (LOI) and find that the composition is equivalent to a high silica andesite. Conflow implements the MELTS algorithm to minimize the energy of the silicate melt-water mixture using laboratory values for the themodynamic properties [Ghiorso and Sack, 1995]. The energy minimization yields the water solubility at a given pressure, temperature and composition. The result is then used to calculate the viscosity for the appropriate composition in accordance with Shaw [1972]. MELTS also calculates the melt density at the prescribed temperature, pressure and water content by again combining empirical laboratory data with themodynamic constraints.

[70] The volume percentage of survivor grains from the pre-melted structure was measured in thin sections. The resulting percentage of clasts during melt mobilization is $\ll 10 \%$, therefore, the melt viscosity is a good indicator of the mixture viscosity. At the emplacement conditions (380 MPa, water-saturated), the temperature must be $1450^{\circ} \mathrm{C}$ to achieve a viscosity of $1 \mathrm{~Pa}$ s with $10 \%$ solid fragments.

[71] Acknowledgments. Field work and data analysis supported by NSF Grants OCE-0203664 and OCE-0549017. We thank G. Di Toro and $R$. Fletcher for helpful and extremely thoughtful commentary on an early draft of the manuscript. We particularly are grateful to R. Fletcher for helping with the derivation of the non-Newtonian case under basic shear. Comments by the Associate Editor, K. Ujiie and an anonymous reviewer further improved the work.

\section{References}

Abercrombie, R. E., et al. (Eds.) (2006), Earthquakes: Radiated energy and the physics of faulting, Geophys. Monogr. Ser., vol. 170.

Allen, J. R. L. (1982), Sedimentary Structures: Their Character and Physical Basis, vol. 2, 663 pp., Elsevier, New York.

Allen, J. R. L. (1985), Principles of Physical Sedimentology, George Allen and Unwin, Boston, $272 \mathrm{pp}$.
Andrews, D. J. (2002), A fault constitutive relation accounting for thermal pressurization of pore fluid, J. Geophys. Res., 107(B12), 2363, doi:10.1029/2002JB001942.

Anketell, J. M., and S. Dzulynski (1968), Transverse deformational patterns in unstable sediments, Ann. Soc. Geol. Pol., 38, 411-416.

Anketell, J. M., et al. (1970), On the deformational structures in systems with reversed density gradients, Ann. Soc. Geol. Pol., 40, 3-30.

Bagnold, R. A. (1956), The flow of cohesionless grains in fluids, Philos. Trans. R. Soc. London, Ser. A, 249(964), 235-297.

Berner, H., et al. (1972), Diapirism in theory and experiment, Tectonophysics, 15, 197-218.

Bhattacharya, H. N., and S. Bandyopadhyay (1998), Seismites in a Proterozoic tidal succession, Singhbhum, Bihar, India, Sediment. Geol., 119, $239-252$.

Biegel, R. L., and C. G. Sammis (2004), Relating fault mechanics to fault zone structure, Adv. Geophys., 47, 65-111.

Brodsky, E. E., and H. Kanamori (2001), Elastohydrodynamic lubrication of faults, J. Geophys. Res., 106(B8), 16,357-16,374.

Brodzikowski, K., and A. Haluszczak (1987), Flame structures and associated deformations in Quaternary glaciolacustrine and glaciodeltaic deposits: Examples from central Poland, Geol. Soc. Lond. Spec. Publ., 29(1), 279-286.

Byerlee, J. D. (1970), Static and kinetic friction of granite at high normal stress, Inst. J. Rock Mech. Min. Sci., 7, 3821-3827.

Byrne, T. (1984), Early deformation in melange terranes of the Ghost Rocks Formation, Kodiak Islands, Alaska (Special Paper), Geol. Soc. Am., 198, $21-51$.

Chandrasekhar, S. (1961), Hydrodynamic and Hydromagnetic Stability, Dover, Mineola, New York.

Clifton, H. E. (1984), Sedimentation units in stratified resedimentation conglomerate, Paleocene submarine canyon fill, Point Lobos, California, paper presented at Sedimentology of Gravels and Conglomerates, Memoir-Canadian Society of Petroleum Geologists, Hamilton, ON, Canada, 22-27 Aug. 1982.

Collinson, J. (1994), Sedimentary deformational structures, in The Geological Deformation of Sediments, edited by A. Maltman, pp. 95-125, Chapman and Hall, London, U.K.

Conrad, C. P., and P. Molnar (1997), The growth of Rayleigh-Taylor-type instabilities in the lithosphere for various rheological and density structures, Geophys. J. Int., 129, 95-112.

Cowan, D. S. (1999), Do faults preserve a record of seismic slip? A field geologist's opinion, J. Struct. Geol., 21(8-9), 995-1001.

Dasgupta, P. (1998), Recumbent flame structures in the Lower Gondwana rocks of the Jharia Basin, India-A plausible origin, Sediment. Geol., $119,253-261$.

Davis, G. H., and S. J. Reynolds (1996), Structural Geology of Rocks and Regions, 2nd ed., John Wiley, Hoboken, N. J.

Di Toro, G., et al. (2005), Can pseudotachylytes be used to infer earthquake source parameters? An example of limitations in the study of exhumed faults, Tectonophysics, 402(1-4), 3-20.

Dieterich, J. H., and E. T. Onat (1969), Slow finite deformations of viscous solids, J. Geophys. Res., 74(8), 2081-2088.

Fialko, Y., and Y. Khazan (2005), Fusion by earthquake fault friction: Stick or slip?, J. Geophys. Res., 110, B12407, doi:10.1029/2005JB003869.

Ghiorso, M. S., and R. O. Sack (1995), Chemical mass transfer in magmatic processes. IV: A revised and internally consistent thermodynamic model for the interpolation and extrapolation of liquid-solid equilibria in magmatic systems at elevated temperatures and pressures, Contrib. Mineral. Petrol., 119, 153-166.

Horváth, Z., et al. (2005), Soft-sediment deformation structures in the Late Miocene-Pleistocene sediments on the pediment of the Mátra Hills (Visonta, Atkár, Verseg): Cryoturbation, load structures or seismites?, Tectonophysics, 410, 81-95.

Johnson, A. M., and R. C. Fletcher (1994), Folding of Viscous Layers: Mechanical Analysis and Interpretation of Structures in Deformed Rock, Columbia Univ. Press, New York.

Kelling, G., and E. K. Walton (1957), Load-cast structures; their relationship to upper-surface structures and their mode of formation, Geol. Mag., 94(6), 481-490.

Lachenbruch, A. H., and J. H. Sass (1980), Heat flow and energetics of the San Andreas fault zone, J. Geophys. Res., 85(B11), 6185-6222.

Lachenbruch, A. H., and J. H. Sass (1992), Heat flow from Cajon Pass, fault strength, and tectonic implications, J. Geophys. Res., 97(B4), 4995-5015.

Lin, A. (2007), Fossil Earthquakes: The Formation and Preservation of Pseudotachylytes, 348 pp., Springer, Berlin, Germany.

Lowe, D. R. (1975), Water escape structures in coarse-grained sediments, Sedimentology, 22(2), 157-204.

Magloughlin, J. F. (1992), Microstructural and chemical-changes associated with cataclasis and frictional melting at shallow crustal levels - The cataclasite pseudotachylyte connection, Tectonophysics, 204(3-4), 243-260. 
Magloughlin, J. F., and J. G. Spray (1992), Frictional melting processes and products in geological-materials-Introduction and discussion, Tectonophysics, 204(3-4), 197-206.

Major, J. J., and T. C. Pierson (1992), Debris flow rheology: Experimental analysis of fine-grained slurries, Water Resour. Res., 28(3), 841-857.

Maltman, A. (1994), Introduction and overview, in The Geological Deformation of Sediments, edited by A. Maltman, Chapman and Hall, London, $362 \mathrm{pp}$.

Mastin, L. G., and M. S. Ghioroso (2000), A numerical program for steadystate flow of magma gas mixtures through vertical eruptive conduits, U.S Geol. Surv. Open File Rep. 00-209.

Meneghini, F., et al. (2007), Unraveling seismic deformation in exhumed subduction thrusts: The ultrafine-grained fault rocks of Pasagshak Point, Kodiak Island, AK (abstracts with programs), Geol. Soc. Am., 39, 374.

Meneghini, F., et al. (2008), Picturing the seismic cycle along ancient decollement thrusts: The ultrafine-grained fault rocks of Pasagshak Point, Kodiak Island, AK, Trab. Geol., in press.

Mikaelian, K. O. (1996), Rayleigh-Taylor instability in finite-thickness fluids with viscosity and surface tension, Phys. Rev. E: Stat. Phys., Plasmas, Fluids, Relat. Interdiscip. Top., 54, 3676-3680.

Nielsen, S., et al. (2008), Frictional melt and seismic slip, J. Geophys. Res., 113, B01308, doi:10.1029/2007JB005122.

Otsuki, K., et al. (2003), Fluidization and melting of fault gouge during seismic slip: Identification in the Nojima fault zone and implications for focal earthquake mechanisms, J. Geophys. Res., 108(B4), 2192, doi:10.1029/2001JB001711.

Owen, G. (1987), Deformation processes in unconsolidated sands, Geol. Soc. Lond. Spec. Publ., 29(1), 11

Owen, G. (1996), Experimental soft-sediment deformation: Structures formed by the liquefaction of unconsolidated sands and some ancient examples, Sedimentology, 43(2), 279-293.

Plafker, G., et al. (1994), Geology of the southern Alaska margin, in The Geology of Alaska, The Geology of North America, edited by G. Plafker and H. C. Berg, pp. 389-449, Geol. Soc. of Am., Boulder, Colo.

Potter, P. E., and F. J. Pettijohn (1977), Paleocurrents and Basin Analysis, 2nd ed., Springer-Verlag, New York.

Rice, J. R. (2006), Heating and weakening of faults during earthquake slip, J. Geophys. Res., 111, B05311, doi:10.1029/2005JB004006.

Ronnlund, P. (1989), Viscosity ratio estimates from natural Rayleigh-Taylor instabilities, Terra Nova, 1, 334-348.

Rowe, C. D. (2007), Snapshots of the Earthquake Cycle: An Approach to Subduction Zone Paleo-Seismicity, 185 pp., UC Santa Cruz, Santa Cruz, Calif.

Rowe, C. D., et al. (2005), Large-scale pseudotachylytes and fluidized cataclasites from an ancient subduction thrust fault, Geology, 33, 937-940.
Sample, J., and D. Fisher (1986), Duplex accretion and underplating in an ancient accretionary complex, Kodiak Islands, Alaska, Geology, 14, $160-163$.

Shaw, H. (1972), Viscosities of magmatic silicate liquids; an empirical method of prediction, Am. J. Sci., 272, 870-898.

Sibson, R. H., and V. G. Toy (2006), The habitat of fault-generated pseudotachylyte: Presence vs. absence of friction-melt, in Earthquakes. Radiated Energy and the Physics of Faulting, edited by R. Abercrombie et al., AGU, p. 153-166, Washington, D. C.

Smith, R. B. (1977), Formation of folds, boudinage, and mullions in nonNewtonian materials, Geol. Soc. Am. Bull., 88, 312-320.

Sonder, I., et al. (2006), Non-Newtonian viscosity of basaltic magma, Geophys. Res. Lett., 33, L02303, doi:10.1029/2005GL024240.

Song, C., et al. (2008), A phase diagram for jammed matter, Nature, 453(7195), 629-632.

Spray, J. G. (2005), Evidence for melt lubrication during large earthquakes, Geophys. Res. Lett., 32, L07301, doi:10.1029/2004GL022293.

Turcotte, D. L., and G. Schubert (2002), Geodynamics, 2nd ed., Cambridge Univ. Press, New York.

Twiss, R. J., and E. M. Moores (1992), Structural Geology, W. H. Freeman, New York.

Ujiie, K., et al. (2007a), Fluidizatian of granular material in a subduction thrust at seismogenic depths, Earth Planet. Sci. Lett., 259, 307-318.

Ujiie, K., et al. (2007b), Pseudotachylytes in an ancient accretionary complex and implications for melt lubrication during subduction zone earthquakes, J. Struct. Geol., 29, 599-613.

Visher, G. S., and R. D. Cunningham (1981), Convolute laminations-a theoretical analysis: Example of Pennsylvanian sandstone, Sed. Geol., 28, $175-188$.

Vrolijk, P., P. G. Myers, and J. C. Moore (1988), Warm fluid migration along tectonic melanges in the Kodiak accretionary complex, Alaska, J. Geophys. Res., 93(B9), 10,313-10,324.

Wenk, H. R., et al. (2000), Pseudotachylites in the eastern peninsular ranges of California, Tectonophysics, 321(2), 253-277.

Wilcock, W. S. D., and J. A. Whitehead (1991), The Rayleigh-Taylor instability of an embedded layer of low-viscosity fluid, J. Geophys. Res., 96(B7), 12,193-12,200.

Yuan, F., and V. Prakash (2008), Slip weakening in rocks and analog materials at co-seismic slip rates, J. Mech. Phys. Solids, 56(2), 542-560.

E. E. Brodsky, F. Meneghini, and J. C. Moore, Department of Earth and Planetary Science, University of California, 1156 High St., Santa Cruz, CA 95060, USA. (brodsky@pmc.ucsc.edu)

C. D. Rowe, Department of Geological Sciences, University of Cape Town, Cape Town, South Africa. 